\title{
Some Protozoan Parasites Infecting Blood of Camels (Camelus dromedarius) at Assiut Locality, Upper Egypt
}

Barakat Shehata Abd-Elmaleck ${ }^{1 *}$, Gamal Hassan Abed ${ }^{1}$ and Ahmed Mohammad Mandour ${ }^{2}$

${ }^{1}$ Zoology Department, Faculty of Science, Assiut University, Assiut, 71516, Egypt

${ }^{2}$ Parasitology Department, Faculty of Medicine, Assiut University, Assiut, 71516, Egypt

\begin{abstract}
Out of ninety eight of camels (Camelus dormadarius) examined, only forty eight (48.9\%) were found to be infected with blood protozoan parasites (Trypanosoma evansi, Theileria sp. and Babesia sp.). The higher incidence of infection were found in males $(36.7 \%)$ whereas, $(12.24 \%)$ in females. Microscopical examination revealed that longitudinal binary fission, the stumpy, slender forms of Trypanosoma evansi, trophozoites of both Theileria sp. And Babesia sp. Experimental infection revealed that both of Babesia and Theileria have a zoonotic importance for their transmissible to the experimental animals.
\end{abstract}

Keywords: Camelus dormaderius; Surra; Babesia; Piroplasms; Theileria

\section{Introduction}

Camel (Camelus dromedarius) is an important multipurpose animal in arid and semi-arid areas of the world [1]. Protozoal diseases particularly trypanosomosis, cause remarkable losses on animal production in all the tropical and subtropical area. Trypanosomosis in camels is caused by Trypanosoma evansi and is transmitted from camel to camel by a number of species of haematophagous biting flies including Tabanus, Stomoxys, Lyperosiaand Haematobia [2]. Animal African trypanosomosis is a serious constraint to livestock sector development in sub-Saharan Africa. The disease, mainly caused by $T$. congolense, has a limitation in its diagnosis and treatment [3]. Trypanosomosis caused by T. evansi is the most recognized protozoan disease of camels and causes a disease known as Surra [4]. Surra has been reported in Pakistan [5], Jordan [6], Kenya [7], and many African countries. An outbreak of abortion and neonatal mortality associated with $T$. evansi infection in dromedary camels has been reported in Canary Islands [8].

Equine babesiosis is an infectious disease of horses and other equips caused by the protozoan hemoparasites $B$. equi and B. caballi [9]. B. equi infects $90 \%$ of the world equine populations [10], and transmitted naturally by the ticks of the Genera Hyalomma, Dermacentor and Rhipicephalus [11], and experimentally by Boophilus microplus [12]. B. equi was first isolated in Brazil by Ribeiro, et al. [13] from naturally infected horses to produce an antigen for serologicaly purposes. Babesiosis is vectored to humans by ticks that are ectoparasites of rodents [14]. Human babesiosis caused by B. microti was first described from sites along the North Eastern United States terminal moraine [15] and later from Minnesota and Wisconsin [16]. $B$. bovis and B. bigemina, exhibit a typical apicomplexan life cycle characterized by merogony, gametogony and sporogony [17]

The disease caused by the apicomplexan protozoan parasite Theileriaparva, known as East Coast fever or Corridor disease, is one of the most serious cattle diseases in Eastern, Central, and Southern Africa [18]. Hemoparasites known to infect bovine erythrocytes and cause anemia include organisms from the genera Anaplasma, Eperythrozoon, B., and Th. [19].

Accordingly the aim of the present work is to differentiate between different forms of T. evansi, to describe Th. and B. sp. as new species Infecting Camelus dromedaries using light and electron microscopy and to examine the zoonotic importance for these parasites on the experimental animals (White rates and mices).

\section{Materials and Methods}

Out of 98 blood samples of camels (Camelus dromedarius) examined for blood protozoan parasites collected from different localities of Sloughter houses at Assiut city, Egypt (Dairout, Beni Ady, El ethamna). These freshly collected blood samples were divided in two groups one in a tube coated with EDTA, and the other in a test tube for centrifugation to obtain sera. Thick and thin blood smears were made for morphological examination of some protozoan blood parasites.

\section{Electron microscopic studies}

TEM: Few drops from blood which is highly infected with Trypanosoma, Babesia and Theileria immediately fixed in $3 \mathrm{ml}$. of $3 \%$ glutaraldehyde solution in phosphate buffer (PH 7.2), for 24 hours and kept at $4^{\circ} \mathrm{C}$ in refrigerator. The samples were post fixed in $1 \%$ Osmium tetroxide in phosphate buffer ( $\mathrm{PH} 7.2,300 \mathrm{mom}$ ), for 30 minutes. They were washed several times with phosphate buffer solution. The samples were then embedded in Epon which can preserve fine structure from distortion during processing then ultra-thin sections were cut by an Ultra microtome and examined by JEOL, 100 CXII operating at 80 KV(TEM).

SEM: For scanning electron microscope of blood; few dropswere fixed in $3 \%$ Glutaraldehyde in buffer for 24 hours. Specimens were washed three times in Phosphate buffer and post fixed in $1 \%$ Osmium tetroxide for 2 hours and then washed in the same buffer. They were dehydrated in different grades of ethyl alcohol and then mounted on

*Corresponding author: Barakat Shehata Abd-Elmaleck, Zoology Department, Faculty of Science, Assiut University, Assiut, 71516, Egypt, Tel: 0201113532752; Fax: 002088342708; E-mail: barakatshehata@yahoo.com

Received November 20, 2013; Accepted March 20, 2014; Published March 22 , 2014

Citation: Abd-Elmaleck BS, Abed GH, Mandourt AM (2014) Some Protozoan Parasites Infecting Blood of Camels (Camelus dromedarius) at Assiut Locality, Upper Egypt. J Bacteriol Parasitol 5: 184. doi: 10.4172/2155-9597.1000184

Copyright: () 2014 Abd-Elmaleck BS, et al. This is an open-access article distributed under the terms of the Creative Commons Attribution License, which permits unrestricted use, distribution, and reproduction in any medium, provided the original author and source are credited. 
Citation: Abd-Elmaleck BS, Abed GH, Mandourt AM (2014) Some Protozoan Parasites Infecting Blood of Camels (Camelus dromedarius) at Assiut Locality, Upper Egypt. J Bacteriol Parasitol 5: 184. doi: 10.4172/2155-9597.1000184

special holders and coated with gold. Then they were examined in a JSM-T 200 L.V. 5400 Scanning Electron Microscopy (SEM).

Experimental infection: Two groups of laboratory animals representing in five white from both rates and mices were dispensed with freshly infected blood camels by Babesia and Theileria in three doses each dose $3 \mathrm{ml}$ blood to examine the zoonotic importance for these parasites. Blood examination was performed daily for determine the infection of these laboratory animals.

\section{Results}

Out of ninety eight camels, (Camelus dromedaries) collected from different parts of Assiut (Benny Adie, El-atamna and Dairout). They revealed three genera of parasites including Trypanosoma, Theileria and Babesia

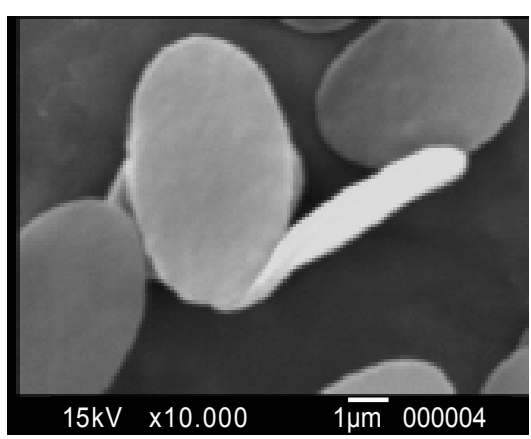

Figure 1: Presence of developmental stages Stumpy forms, Trypomastigote stage with free flagellum, undulating membrane and longitudinal binary fission.

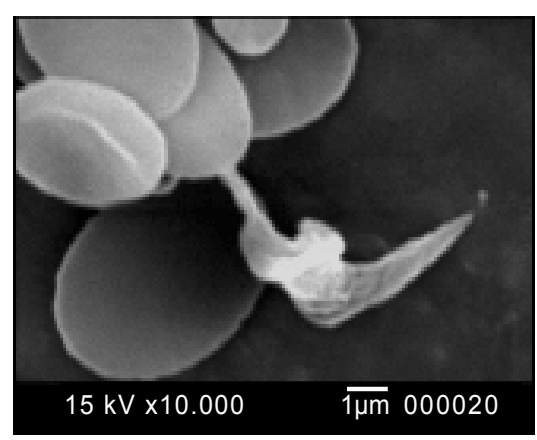

Figure 2: Presence of developmental stages Stumpy forms, Trypomastigote stage with free flagellum, undulating membrane and longitudinal binary fission.

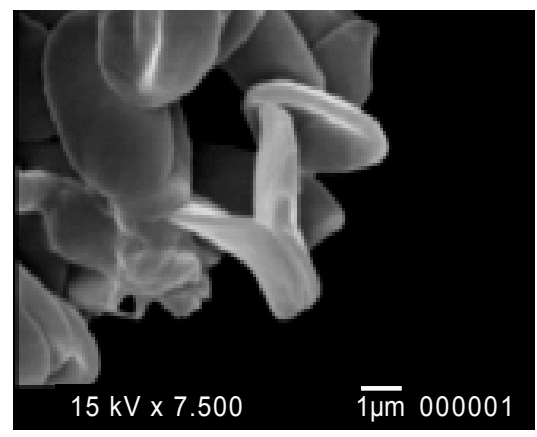

Figure 3: Presence of developmental stages Stumpy forms, Trypomastigote stage with free flagellum, undulating membrane and longitudinal binary fission.

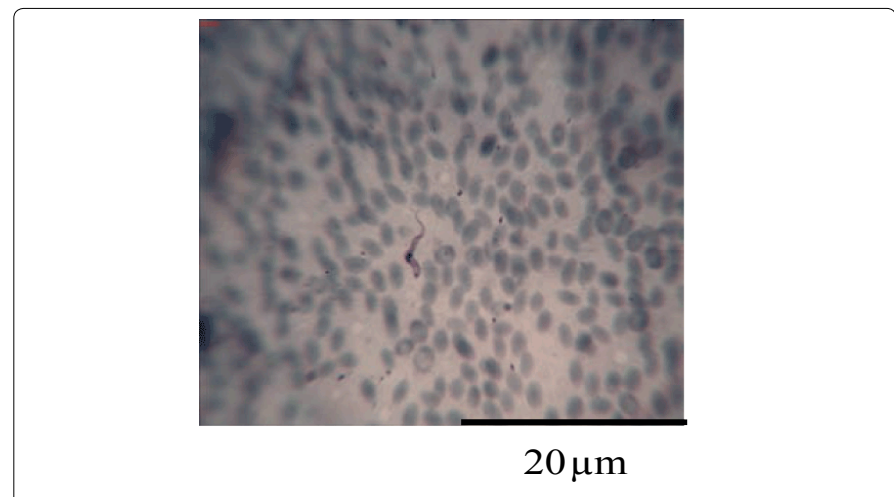

Figure 4: Free flagellum length $7 \mu \mathrm{m}$ with two small folds of undulating membrane.

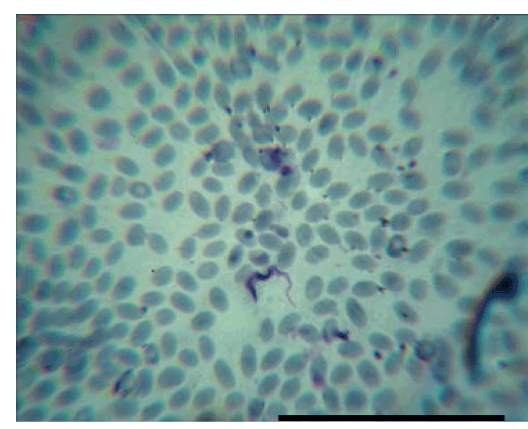

$20 \mu \mathrm{m}$

Figure 5: Free flagellum $8 \mu \mathrm{m}$ with one to two small folds

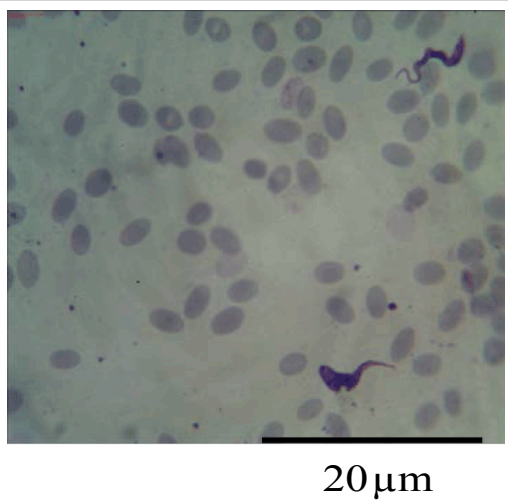

Figure 6: Eight with no folds.

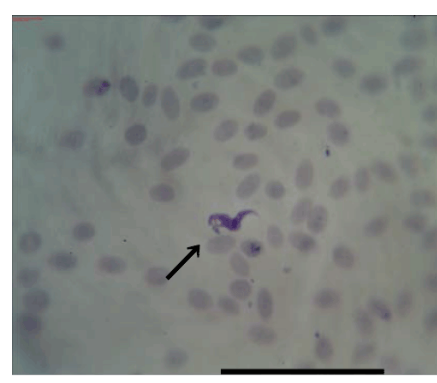

$20 \mu \mathrm{m}$

Figure 7: 17-20 with pulp body shape. 
Citation: Abd-Elmaleck BS, Abed GH, Mandourt AM (2014) Some Protozoan Parasites Infecting Blood of Camels (Camelus dromedarius) at Assiut Locality, Upper Egypt. J Bacteriol Parasitol 5: 184. doi: 10.4172/2155-9597.1000184

Page 3 of 7

\section{Trypanosoma sp.}

Trypanosoma evansi is similar in shape with $T$. evansi in all mammals although it is different in size. Three camels from 98 (3.06 $\%)$ were infected. SEM revealed that presence of developmental stages Stumpy forms, Trypomastigote stage with free flagellum, undulating membrane and longitudinal binary fission as in Figures 1-3 respectively. They are five different forms according to the different morphological features (Total length, Total width, Nucleus index, the distance between (Kinetoplast to the posterior end, Nucleus to the anterior end, Nucleus to the posterior end),Presence of free flagellum, Presence of undulating membrane and the shape of posterior end) Figures 4-8 as in Table 1.

\section{Babesia sp.}

Forty six from ninety eight examined of Camellus dromedaries (46.9\%) were found infected with Babesia sp. It infects the camels by ticks with heavy infections as Figure 9 in the intra and extra of the red blood corpuscles (Figures 10 and 11) respectively and showing that

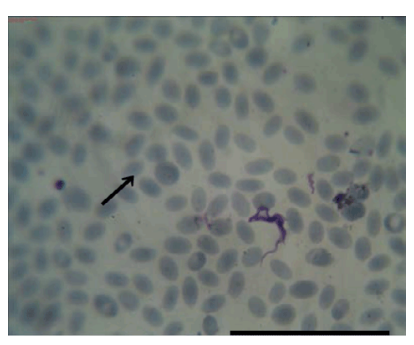

$20 \mu \mathrm{m}$

Figure 8: 10-12 with well-developed undulating membrane with two to four folds.

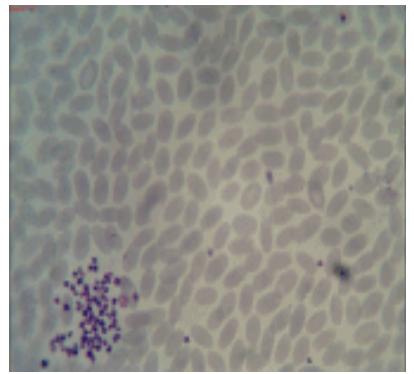

Figure 9: Babesia sp infects the camels by ticks with heavy infections in the intra and extra of the red blood corpuscles. different stages as ray body (Figures 12). The infection by the parasite sometimes accompanied by the infection with Theileria sp. SEM and TEM, reveal the sporokinetes of $B$. have elongate shape, $3.12 \mu \mathrm{m}$ long and $1.56 \mu \mathrm{m}$ wide, being wider at the anterior end and containing a single nucleus, large endoplasmic reticulum and abundant micronemes which was concentrated at the anterior end as in Figures 13 and 14

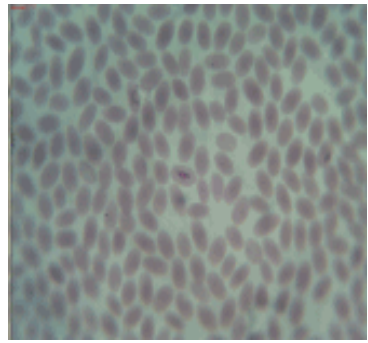

Figure 10: Babesia sp infects the camels by ticks with heavy infections in the intra and extra of the red blood corpuscles

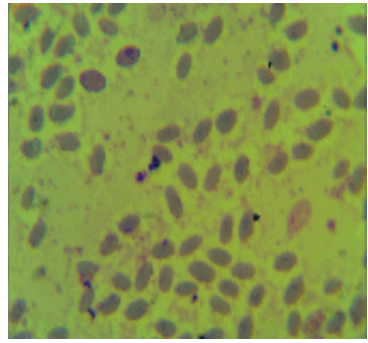

Figure 11: Babesia sp infects the camels by ticks with heavy infections in the intra and extra of the red blood corpuscles

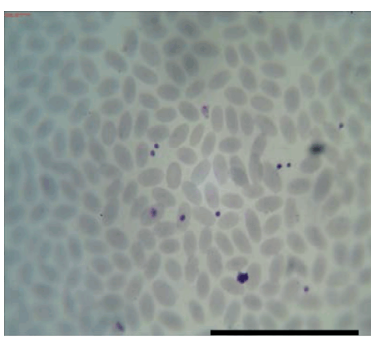

$20 \mu \mathrm{m}$

Figure 12: Different stages as ray body.

\begin{tabular}{|c|c|c|c|c|c|}
\hline Type or form No & 1 & 2 & 3 & 4 & 5 \\
\hline Total length & $23-30$ & $20-27$ & $28-30$ & $20-30$ & $36-44$ \\
\hline Total width & $2.5-5$ & 4-Mar & 6-Apr & $13.5-20$ & 7-May \\
\hline Nucleus index & $6 \times 2.5$ & $2 \times 5$ & $2.5 \times 4$ & $4 \times 4$ & $3 \times 6$ \\
\hline Kinetoplast to the posterior end & 2 & 4 & Contact with it & 13-Oct & 5-Mar \\
\hline $\begin{array}{l}\text { Free flagellum and undulating } \\
\text { membrane }\end{array}$ & \begin{tabular}{|l|} 
Free flagellum length 7 \\
$\mu \mathrm{m}$ with two small folds \\
of undulating membrane
\end{tabular} & $\begin{array}{l}\text { Free flagellum } 8 \mu \mathrm{m} \text { with } \\
\text { one to two small folds }\end{array}$ & 8 with no folds & $17-20$ with pulp body shape & $\begin{array}{l}\text { 10-12 with well-developed } \\
\text { undulating membrane with } \\
\text { two to four folds }\end{array}$ \\
\hline Shape of the posterior end & Pointed posterior end & Sharp posterior end & $\begin{array}{l}\text { Truncated posterior } \\
\text { end }\end{array}$ & $\begin{array}{l}\text { Vacoulated like structure with } \\
\text { granules }\end{array}$ & Normal posterior end \\
\hline Nucleus to posterior end & 15 & 15 & 8 & 3 & 15 \\
\hline Nucleus to anterior end & 7 & 13 & 8 & 12 & 10 \\
\hline Figs. no. & Figure (4) & Figure (5) & Figure (6) & Figure (7) & Figure (8) \\
\hline
\end{tabular}

Table 1: Showing differences between different forms of T. evansi (measurements with $\mu \mathrm{m}$ ). 


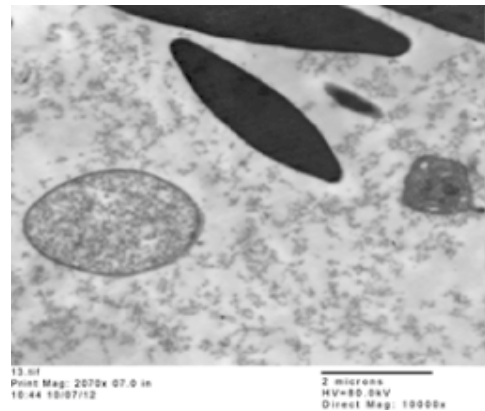

Figure 13: SEM and TEM, reveal the sporokinetes.

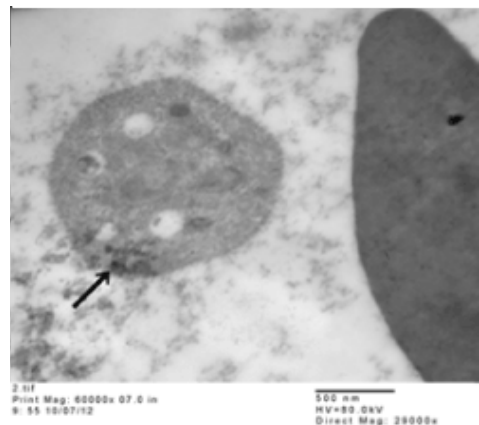

Figure 14: SEM and TEM, reveal the sporokinetes.

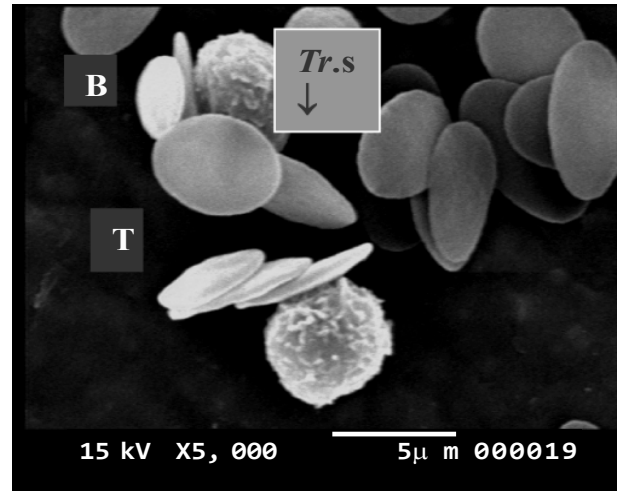

Figure 15: Sporokinetes having oval or elongate shapes

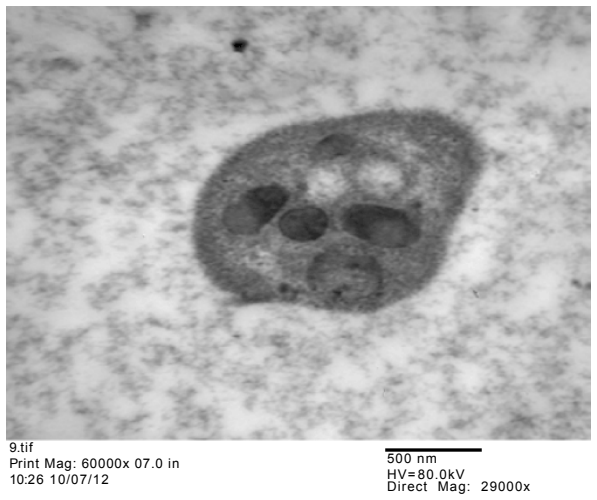

Figure 16: Transverse sections of sporokinetes.

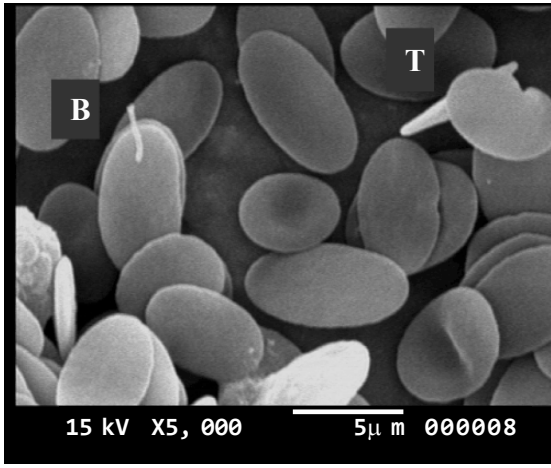

Figure 17: Concomitant invaginations of the plasma membranes of the erythrocyte and the parasite.

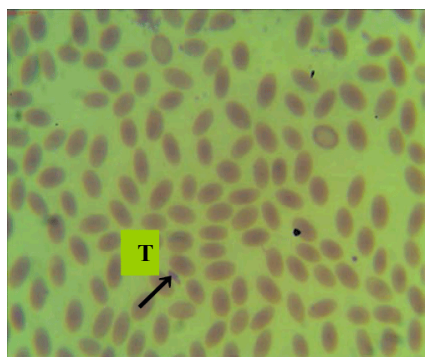

$20 \mu \mathrm{m}$

Figure 18: Trophozoite stages intra and extra of the red blood corpuscles.

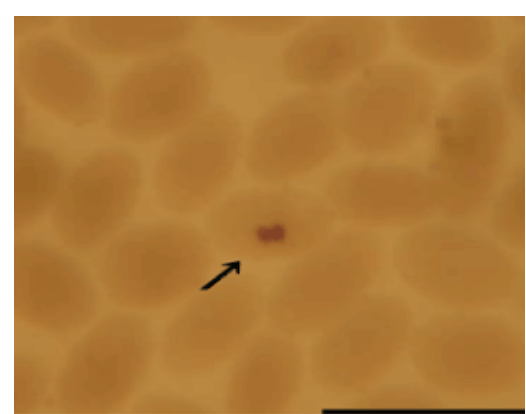

$20 \mu \mathrm{m}$

Figure 19: Blood films which stained with Giemsa contained Th. piroplasms including, cocci and comma shaped.

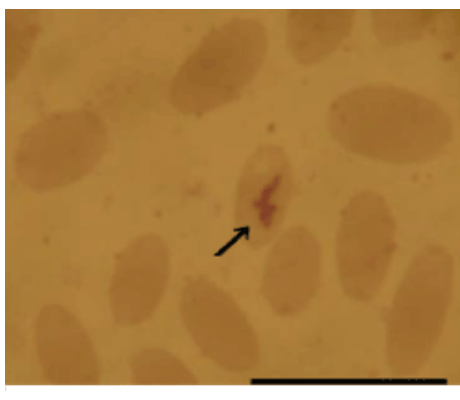

$20 \mu \mathrm{m}$

Figure 20: Blood films which stained with Giemsa contained Th. piroplasms including, cocci and comma shaped. 


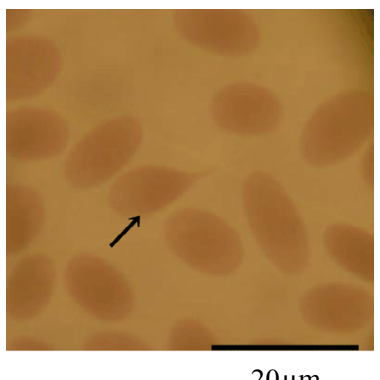

$20 \mu \mathrm{m}$

Figure 21: Abnormalities in erythrocyte structure included acanthocytosis.

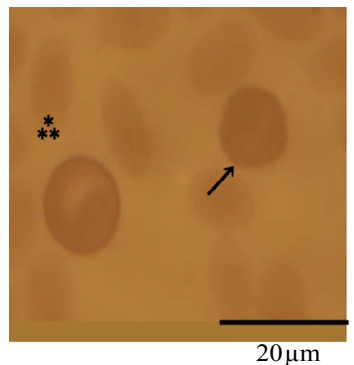

Figure 22: Spherocytosis and basophilic stippling.

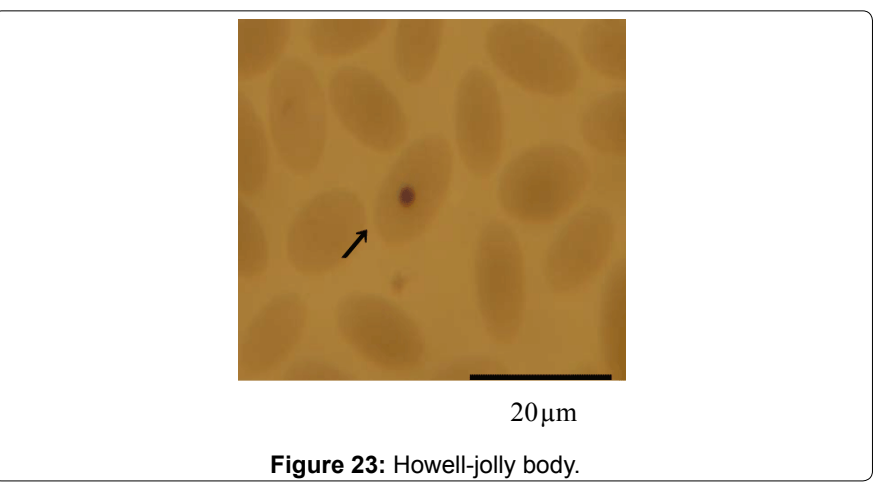

Figure 23: Howell-jolly body.

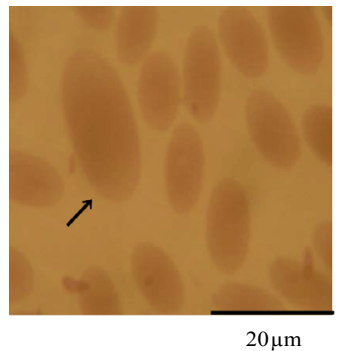

Figure 24: Macrocyte.

The Encephalitozoon - like microsporidia are present within the same specimen in which sporokinetes of $B$. caballiare found. They presented different morphological stages, suggesting a sequential phases of development. All stages contained a single nucleus. Sporonts have thicker and more electron-dense walls due to deposition of granules on the surface of the parasite. They have oval or elongate shapes (Figure 15). The sporonts multiplied producing the sporoblasts with polar filament. In the transverse sections, four coils of the polar tube and two food vacuoles were observed (Figure 16). Also, the scanning electron microscope show the trophozoites located very close to the erythrocyte membrane presented a tubular feeding structure, which emerged from the interior of the parasite and extended to the blood plasma, the tubular feeding structure was formed by the concomitant invaginations of the plasma membranes of the erythrocyte and the parasite Figure 17.

\section{Theileria sp.}

Only nine from ninety eight Camelus dromedarius (9.18\%) are infected with the parasite. Trophozoite is a cigarette shaped and the light microscope shows some stages intra and extra of the red blood corpuscles as in Figure 18. Initial blood films examination revealed anemia, thrombocytosis and leukocytosis. Also, blood films which stained with Giemsa contained Th. piroplasms including, cocci Figure 19 and comma shaped Figure 20. Other abnormalities in erythrocyte structure included acanthocytosis Figure 21, spherocytosis and basophilic stippling, Figure 22, Howell-jolly body's Figure 23 and macrocyteas in Figure 24. Scanning electron microscopy also shows many different developmental stages.

\section{Experimental infection}

Theileria and Babesia were appeared in both of the white rates and mice after 24 days of infection but 3 mice died after 80 days of infection. Rates could tolerate the infection with appearing of some symptoms such as diarrhea and a very reddish color for rates eyes. Some different stages of both parasites at different times appeared after 44, 59 and 74 days of infection as in Figures 25 A-D. This experimental infection had been proved that both of Theileria and Babesia have zoonotic importance whatever for that, of a very economic importance in the life experimental field.

\section{Discussion}

\section{Trypanosomaevansi}

Trypanosomes of the section salivaria might or might not possess a free flagellum, their kinetoplast is terminal or subterminal in position and the posterior end of the parasite is usually rounded [20]. Several studies have observed a significant morphological difference in some T. evansi isolates $[21,22]$. The presence of vacuoles in T. evansi has been reported (ID and International Medicine Parasitology Volume 1 for web, 2008). In the present work T. evansi measured 20-44 $\mu \mathrm{m}$ in length, agreement with some species described by Hoare CA [23]. Although the main morphological parameters (total length with flagellum, total width, nuclear index, posterior end to the kinetoplast, free flagellum, shape of the posterior end, posterior end to the nucleus, and the nucleus to the anterior end) show some few differences with other data reported by authors Silva RAS, et al. and Sarataphan N, et al. $[10,24]$. The subgenus Duttonella trypanosomes have feebly developed undulating membranes and a large kinetoplast. The latter feature could resemble those of form 5 in the present study, but the undulating membrane contains two or three big fold sand its pointed posterior end is different from T. vivax $[8,23,25]$. By contrast, forms 3 and 4 showed rounded posterior extremity but the most important feature the Duttonella trypanosomes, the large kinetoplast, was absent [23]. The results obtained in the present study would indicate that biometrically distinct $T$. evansi could also be found in the same area and even in the same animal species.

\section{Babesia sp.}

Ticks are widespread in camel habitats. They cause serious adverse 


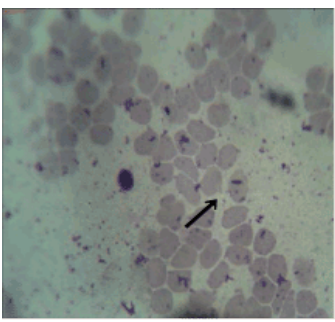

A

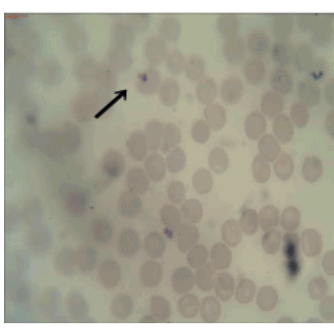

$\mathbf{B}$

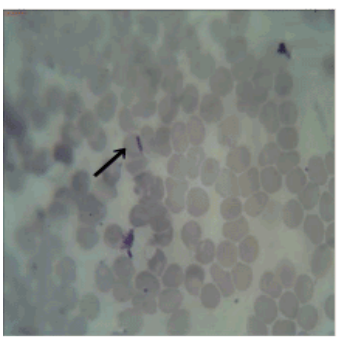

C

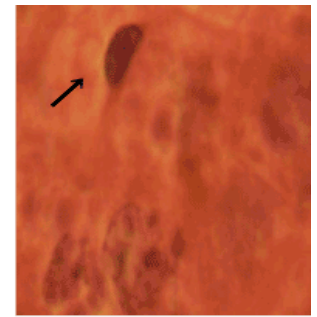

$\mathbf{D}$
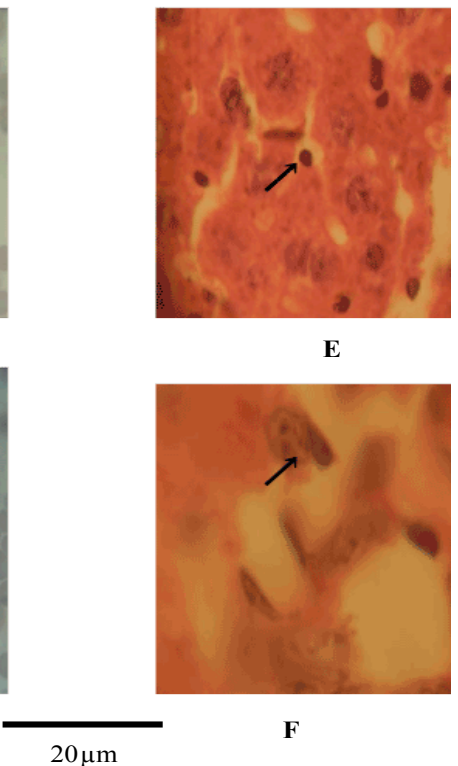

Figure 25: Different stages of both parasites at different times appeared after 44,59 and 74 days of infection.

effects such as anemia, dermatitis, mastitis reduced meat and milk production and low quality hides [26]. Camels were infected with Babesia caballi for the first record in Sudan [26]. So, that the infection of Camelus dromedaries by Babesia sp. is the first record in Egypt. Babesia caballi is a hemoparasitic protozoan of the Phylum Apicomplexa that is transmitted naturally in New World by Anocentor nitens ticks [2]. Few papers have reported the multiplication of $B$. caballi in ticks and most of them were based on optic microscopy [27]. Only one paper on ultrastructure has used transmission electron microscopy to describe the development of B. caballi in salivary glands of Hyalomma truncayum [28]. The forms of B. sp. which are found in Camelus dromedarius in the present study are in agreement with those describe by Ribeiro, et al. [13] within the same cells infected with B. caballi sporokinetes or in other neighbor cells, it was observed that microsporidia organisms were undergoing different stages of development. Ultra-structural analysis showed that all stages of development of microsporidia with a single nucleus, while the stages of the sporoblast and spore had four coils of the polar tubes. Based on these findings, the microsporidia could be classified as Encephalitozoon cuniculi [29]. Encephalitozoon cuniculi infections were described in mammals, including horses, causing asymptomatic infections in immunocompetent hosts [4]. So that, according to the present work there are two species of $B$. one is $B$. caballi and the other B. equi. Which have two vacuoles.

\section{Theileria sp.}

Taxonomic classification of Theileria sp. was based on microscopic appearance of intraerythrocytic piroplasms, geographical location of the infected animal apparent pathogenicity of the organism and serologic testing [30,31] Most theilerial organisms of cattle that had low pathogenicity were called Th. Mutans [14]. As more Th. sp. were isolated and studied, some organisms were reclassified. For example, the US theilerial organism reported to be T. mutans was renamed $T$. orientalis in 1985 [31].These authors also considered some isolates of Th. orientalis to be the same stocks of $T$. sergent $i$, the name given to a more pathogenic species found in Southeastern Asia. So that, the presence of basophilic stippling indicateda regenerative response consistent with a hemolyticanemia. A combination of spherocytosis and acanthocytosis indicated intravascular erythrocyte fragmentation. Spherocytes can also be formed by immune-mediated processes. There is no evidence of blood loss, but there was a hypoprotienemia. For the first time theilerial infection in camels occurs in Egypt but intraerythrocytic piroplasms were highly pleomorphic, and rod forms were most common. Piroplasms shape may vary with stage of an infection and thus is not a reliable criterion of species differentiation [31]. Thus, the present study suggests that this Species is Theileria camelli.

\section{Conclusions}

The higher incidence of the infected camels with protozoan parasites in Egypt is (48.9\%) due to some environmental conditions. It is the first time in Egypt to record infections of camels with both $B$. $s p$ and Th. $s p$. with higher incidence $(46.9 \%$ and $9.18 \%)$ respectively resulting from their habitat with other animals (cattle's and sheep's).

\section{References}

1. Roby TO, Anthony DW (1963) Transmission of equine piroplasmosis by Dermacentor nitens Neumann. J Am Vet Med Assoc 142: 768-769.

2. Stewart NP, Uilenberg G, de Vos AJ (1996) Review of Australian species of Theileria, with special reference to Theileria buffeli of cattle. Trop Anim Health Prod 28: 81-90.

3. Levkutová M, Hípiková V, Faitelzon S, Benath G, Paulík S, et al. (2004) Prevalence of antibodies to Encephalitozoon cuniculi in horses in the Israel. Ann Agric Environ Med 11: 265-267.

4. Gutierrez C, Corbera JA, Juste MC, Doreste F, Morales I (2005) An outbreak of abortions and high neonatal mortality associated with Trypanosoma evansi infection in dromedary camels in the Canary Islands. Vet Parasitol 130: 163-168.

5. Abo-Shehada MN, Anshassi H, Mustafa G, Amr Z (1999) Prevalence of Surra among camels and horses in Jordan. Prev Vet Med 38: 289-293.

6. Luckins AG (1992) Protozoan diseases of Camels. In. Proc 6: 23-27.

7. Guerra NC, Junior AB, Santos HP, Abreu-Silva AL, Santos AC (2008) Biometry of Trypanosoma vivax found in a calf in the State of Maranhao, Brazil. Ciencia Rural 38: 833-835.

8. de Waal DT (1992) Equine piroplasmosis: a review. Br Vet J 148: 6-14.

9. Sarataphan N, Vongpakorn M, Nuansrichay B, Autarkool N, Keowkarnkah T, et al. (2007) Diagnosis of a Trypanosoma lewisi-like (Herpetosoma) infection in a sick infant from Thailand. J Med Microbiol 56: 1118-1121.

10. Friedhoff KT (1988) Transmission of Babesia, babesiosis of domestic animals and man. CRC Press, Flor 23-52.

11. Hooshmand-Rad JA, Roux JP, Toccalino PA, Navias JC, Cayo DO (1976) The pathogenesis of anaemia in Theileria annulata infection. Res Vet Sci 20: 324-329.

12. Ribeiro MF, Passos LM (2006) Natural co-infection of Babesia caballi and Encephalitozoon-like microsporidia in the tick Anocentor nitens (Acari: Ixodidae). J Invertebr Pathol 93: 183-185.

13. Steketee RW, Eckman MR, Burgess EC, Kuritsky JN, Dickerson J, et al. (1985) Babesiosis in Wisconsin. A new focus of disease transmission. JAMA 253: 2675-2678.

14. Schein E (1988) Equine babesiosis, In: Ristic M. (ed.) Babesiosis of Domestic Animals and Man. CRC Press, Florida 198-208. 
Citation: Abd-Elmaleck BS, Abed GH, Mandourt AM (2014) Some Protozoan Parasites Infecting Blood of Camels (Camelus dromedarius) at Assiut Locality, Upper Egypt. J Bacteriol Parasitol 5: 184. doi: 10.4172/2155-9597.1000184

15. Spielman A, Wilson ML, Levine JF, Piesman J (1985) Ecology of Ixodes dammini-borne human babesiosis and Lyme disease. Annu Rev Entomol 30: 439-460.

16. Chauvin A, Moreau E, Bonnet S, Plantard O, Malandrin L (2009) Babesia and its hosts: adaptation to long-lasting interactions as a way to achieve efficient transmission. Vet Res 40: 37

17. Hayashida K, Abe T, Weir W, Nakao R, Ito K, et al. (2013) Whole-genome sequencing of Theileria parva strains provides insight into parasite migration and diversification in the African continent. DNA Res 20: 209-220.

18. Conrad PA, Waldrup KA (1993) Babesiosis and theileriosis in free-ranging and captive artiodactylids. Zoo Wild Anim Med 3: 506-511.

19. Hoare CA (1964) Morphological and Taxonomic Studies on Mammalian Trypanosomes. X. Revision of the Systematics. J Protozool 11: 200-207.

20. Dávila AM, Ramirez L, Silva RA (1998) Biometrical alterations of Trypanosoma evansi isolate in laboratory rodents. Vet Parasitol 76: 149-152.

21. Gonzalez JA, Gonzalez AO, Santa Cruz AC, Ortiz JC, Comolli JA, et al. (2003) (Hydrochaeris hydrochaeris) en cautiverlo, de la Provin de comunicationes Cientificas y TechnologicasPN Unisersiteded Nacional del Nordest.

22. Hoare CA (1972) The Trypanosomes of Mammals. J small Anim Pract 1: 749.

23. Shiota T, Kurimoto H, Haguma N, Yoshida Y (1984) Studies on babesia first found in murine in Japan: epidemiology, morphology and experimental infection. Zentralbl Bakteriol Mikrobiol Hyg A 256: 347-355.
24. Dávila A Ramirez L, Silva R (1997) Morphological and biometrical differences among Trypanosoma vivax isolates from Brazil and Bolivia. Mem Inst Oswaldo Cruz 92: 357-358.

25. Abdelrahim IA, Ismail AA, Majiid AM, Mohammed AS, Ibrahim AM, et al. (2009) Detection of Babesia caballi in the one- humped Camel (Camelus dromedaries) using the Reverse Line Block (RLB) in Sudan. Sudan J Vet Res 24: 69-72.

26. Holbrook AA, Anthony DW, Johnson AJ (1968) Observations on the development of Babesia caballi (Nuttall) in the tropical horse tick Dermacentor nitens Neumann. J Protozool 15: 391-396.

27. Blouin EF, De Waal DT (1989) The fine structure of developmental stages of Babesia caballi in the salivary glands of Hyalomma truncatum. Onderstepoort J Vet Res 56: 189-193.

28. SPLITTER EJ (1950) Theileria mutans associated with bovine anaplasmosis in the United States. J Am Vet Med Assoc 117: 134-135.

29. Irvin AD (1987) Characterization of species and strains of Theileria. Adv Parasitol 26: 145-197.

30. Telford SR 3rd, Korenberg El, Goethert HK, Kovalevskiĭ luV, Gorelova NB, et al. (2002) [Detection of natural foci of babesiosis and granulocytic ehrlichiosis in Russia]. Zh Mikrobiol Epidemiol Immunobiol : 21-25.

31. Kuttler KL, Craig TM (1975) Isolation of a bovine Theileria. Am J Vet Res 36: 323-325. 